\title{
Nódulo granulomatoso com Enterobius vermicularis em epíploon simulando metástase de câncer de ovário
}

\author{
Granulomatous nodule with Enterobius vermicularis in epiploon \\ simulating metastasis of ovarian cancer
}

\author{
Vitorino Modesto dos Santos', Márcia Benedita de Oliveira Silva², Jane Monteiro \\ Godoi Bernardes ${ }^{3}$ e Marcus Aurelho de Lima ${ }^{1,3}$
}

\begin{abstract}
Resumo Os autores descrevem caso de enterobíase peritoneal apresentando-se como granuloma necrosante, em adolescente com tumor do seio endodérmico do ovário. O diagnóstico foi estabelecido por biópsia de nódulo do epíploon, durante laparotomia para reestadiamento de câncer de ovário após tratamento clínico. Nódulos granulomatosos peritoneais causados por parasitas podem simular metástases, confundindo 0 estadiamento de neoplasias.
\end{abstract}

Palavras-chaves: Enterobius vermicularis. Enterobíase ectópica. Granuloma. Epíploon. Tumor do seio endodérmico ovariano.

Abstract The authors describe a case of peritoneal enterobiasis presenting as necrotizing granuloma, in a adolescent with tumor of the ovarian endodermic sinus. The diagnosis was established through biopsy of peritoneal nodule, during laparotomy for staging system of ovarian cancer. Granulomatous nodules due to parasites could simulate metastasis, and cause confusion in the staging system for cancer.

Key-words: Enterobius vermicularis. Ectopic enterobiasis. Granuloma. Epiploon. Tumor of the ovarian endodermic sinus.

O parasitismo ectópico por E. vermicularis tem sido raramente descrito e predomina em mulheres em virtude da migração de larvas do ânus para a genitália externa $\mathrm{e}$, por via ascendente, podem chegar à cavidade peritoneal ${ }^{26}$. E. vermicularis tem sido relatado na vagina, endométrio, miométrio, tuba uterina, ovário, mesentério, peritônio, fígado, bexiga, ureter, rim, próstata, baço, pulmão e mama123456789101112131415, mas não há associação desses casos com neoplasia.

Os autores relatam enterobíase em epíploon de uma adolescente de 13 anos, durante investigação de metástase em cavidade abdominal de tumor do seio endodérmico do ovário.

\section{RELATO DO CASO}

Paciente de cor branca, 13 anos, procedente da área rural de Minas Gerais, foi atendida em janeiro de 2000 queixando-se de dor abdominal e emagrecimento de $6 \mathrm{~kg}$ em cinco meses. Relatou uso recente de albendazol para tratamento de verminose. Há um mês, apresentava astenia, febre e aumento progressivo do volume abdominal. Informou que a menarca foi aos 12 anos e o último ciclo menstrual há dois meses. $O$ índice de massa corporal foi $20,36 \mathrm{~kg} / \mathrm{m}^{2}$ e o exame físico apenas evidenciou sinais de ascite.

Os resultados dos exames laboratoriais de rotina e a radiografia de tórax foram normais. $O$ teste de gravidez foi negativo. $O$ exame ultra-sonográfico do abdome revelou massa tumoral no ovário direito medindo 13,5 $x 6,8 \times 12,3 \mathrm{~cm}$ e ascite moderada. Em 31/01/2000 foi realizada ooforectomia direita com diagnóstico anatomopatológico de tumor do seio endodérmico, seguida de quimioterapia adjuvante com bleomicina, etoposido, vimblastina e cisplatina. Após um ano de tratamento, foi submetida à laparotomia (second look) para controle loco-regional da neoplasia ovariana e posterior alta da quimioterapia, quando foi achado nódulo em mesossigmóide de cor pardo-clara e consistência elástica, medindo $0,5 \mathrm{~cm}$ de diâmetro.

\footnotetext{
1. Departamento de Clínica Médica. 2. Disciplina de Parasitologia da Faculdade de Medicina do Triângulo Mineiro. 3. Associação de Combate ao Câncer do Brasil Central, Uberaba, MG.

Endereço para correspondência: Prof. Vitorino Modesto dos Santos. Curso de Pós-Graduação em Patologia/FMTM. R. Getúlio Guaritá 130, Abadia 38025-440, Uberaba, MG.

Tel: 5534 3318-5258, Fax: 5534 3312-6640.

E-mail:parasito_fmtm@mednet.com.br

Recebido para publicação em 17/6/2001.
} 
O exame microscópico do material de biópsia revelou inflamação granulomatosa necrosante e a presença de formas adultas de fêmeas de $E$. vermicularis com útero repleto de ovos assimétricos embrionados e cristas cuticulares longitudinais características desta espécie de helminto (Figura 1). Macroscopicamente, o apêndice e as alças intestinais estavam íntegros, sem qualquer anormalidade.

A paciente está em acompanhamento ambulatorial, evoluindo com bom estado geral e sem queixas.

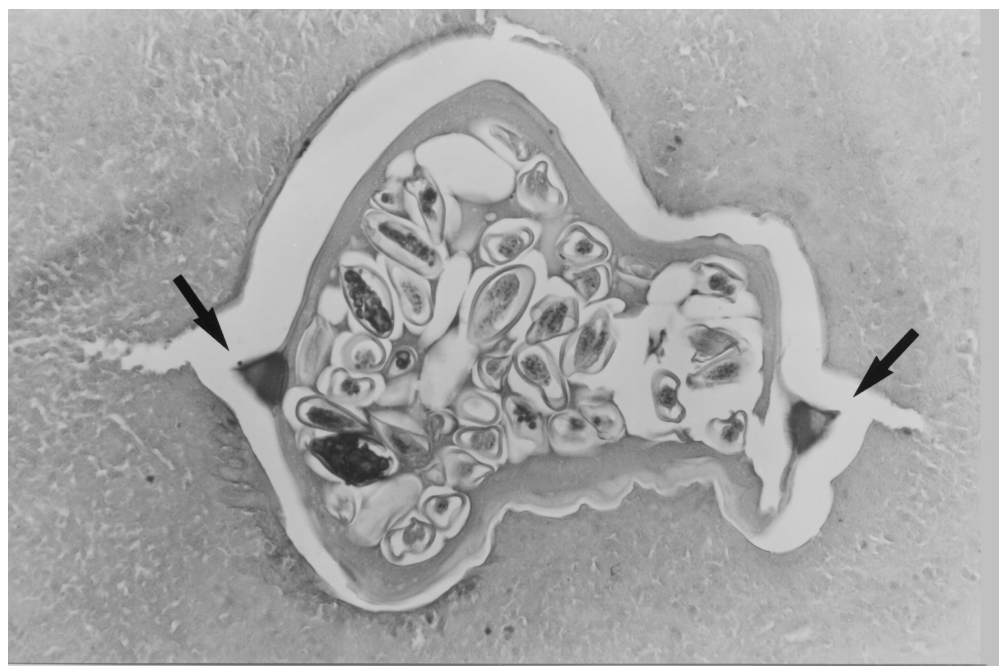

Figura 1 - Granuloma necrosante de epíploon contendo fêmea de E. vermicularis com útero repleto de ovos embrionados de formato assimétrico e as espículas que correspondem às cristas cuticulares longitudinais (setas), que são características desta espécie de helminto (HEx400).

\section{DISCUSSÃO}

No presente caso, o diagnóstico de granuloma por Enterobius vermicularis foi estabelecido pelo achado de fêmea do helminto com ovos embrionados no material de biópsia, durante laparotomia de rotina, em paciente recebendo quimioterapia adjuvante para tratamento de tumor do seio endodérmico de ovário. A maioria dos relatos de granulomas ectópicos provocados por E. vermicularis inclui ovos intactos ou degenerados do parasita, ou a presença de vermes adultos em degeneração ${ }^{11}$, fato que foi observado no presente caso.

Sintomas abdominais causados pela enterobíase intestinal são considerados muito raros ${ }^{10}$; entretanto, ocasionalmente, a presença do parasita tem sido relacionada com apêndices infectados ${ }^{15} 1011$. Reações inflamatórias em localizações ectópicas do helminto podem ocasionar dor abdominal com características de salpingite, ooforite ou epiploíte ${ }^{10}$. Nesta paciente, a dor abdominal e a ascite poderiam estar relacionadas com o tumor ovariano ou com a inflamação no epíploon. O aspecto normal do apêndice e das alças intestinais favorece a hipótese de que o parasita atingiu a cavidade abdominal por migração errática através dos órgãos genitais ${ }^{615}$.

O uso prévio de albendazol ${ }^{6}$ e o achado de lesão granulomatosa sugerem que a localização ectópica do helminto causador da inflamação no epíploon antecedeu o efeito imunodepressor da quimioterapia. Entretanto, não se descarta inteiramente a hipótese de que o desenvolvimento da neoplasia ${ }^{212}$ possa ter, direta ou indiretamente, eventual relação com a ocorrência do fenômeno.

A presença de ascite e linfonodomegalias mesentéricas ${ }^{7}$, ou de nódulos na cavidade abdominal causados por parasitas poderia ser interpretada erroneamente como indicativo de neoplasia e, inclusive, dificultar o estadiamento do tumor em paciente portador de câncer.

\section{REFERÊNCIAS BIBLIOGRÁFICAS}

1. Capaldi M, Roncolini G, Calabrese P, Giordani M, Mendicini AP, Gatto A. Appendiceal oxyuriasis: a case report and review of the literature. Chirurgia Italiana 52:87-89, 2000.

2. Chandrasoma PT, Mendis KN. Enterobius vermicularis in ectopic sites. American Journal of Tropical Medicine and Hygiene 26:644649, 1977.

3. Daly JJ, Baker GF. Pinworm granuloma of the liver. American Journal of Tropical Medicine and Hygiene 33: 62-64, 1984.
4. De Ruiter H, Rijpstra AC, Swellengrebel NH. Ectopic Enterobius vermicularis. Variations in its pattern. Tropical and Geographical Medicine 14:375-380, 1962.

5. Díaz-Pérez R, Cabrera E. Granuloma producido por Enterobius vermicularis en el fondo de saco recto vaginal. Archivos de la Fundación Roux-Ocefa 5:135-138, 1971.

6. Georgiev VS. Chemotherapy of enterobiasis (oxyuriasis). Expert Opinion on Pharmacotherapy 2:267-275, 2001. 
7. Macedo T, MacCarty RL. Eosinophilic ileocolitis secondary to Enterobius vermicularis: case report. Abdominal Imaging 25:530532, 2000.

8. Marteau P, Flourie B, Lavergne A, Garin F, Bertin P, Rambaud JC. Granulome à oxyures du mésentère. Gastroenterologie Clinique et Biologique 13:738-740, 1989.

9. McDonald GSA, Houriane OB. Ectopic Enterobius vermicularis. Gut 13: 621-626, 1972

10. Nutting SA, Murphy F, Inglis FG. Abdominal pain due to Enterobius vermicularis. Canadian Journal of Surgery 23:286-287, 1980

11. Sinniah B, Leopairut J, Neafie RC, Connor DH, Voge M. Enterobiasis: a histopathological study of 259 patients. Annals of Tropical Medicine and Parasitology 85:625-635, 1991.
12. Sun T, Schwartz NS, Sewell C, Lieberman P, Gross S. Enterobius egg granuloma of the vulva and peritoneum: review of the literature. American Journal of Tropical Medicine and Hygiene 45:249-253, 1991.

13. Symmers WCStC. Pathology of oxyuriasis. With special reference to granulomas due to the presence of Oxyuris vermicularis (Enterobius vermicularis) and its ova in the tissues. Archives of Pathology 50:475-516, 1950.

14. Tornieporth NG, Disko R, Brandis A, Barutzki D. Ectopic enterobiasis: a case report and review. Journal of Infection 24:87-90, 1992.

15. Vural S, Tahsinoglu M, Girisken G, Kalaçlar F, Üstündag N. Granuloma in the pouch of Douglas caused by Enterobius vermicularis. Annals of Tropical Medicine and Parasitology 60:125-128, 1966. 